\title{
Cell Therapy for Ischemic Peripheral Neuropathy
}

\author{
Yousuke Katsuda, Ken Arima, Hisashi Kai and Tsutomu Imaizumi \\ Division of Cardio-Vascular Medicine, Department of Medicine, \\ Kurume University School of Medicine
}

Japan

\section{Introduction}

Critical limb ischemia due to chronic peripheral arterial occlusive disease, such as arteriosclerosis obliterans and Buerger's disease (thromboangiitis obliterans), damages peripheral nerves and results in an ischemic neuropathy. Clinical and electro-physiologic features of ischemic neuropathy are sensorimotor polyneuropathy with axonal features as previously reported. In particular, symptoms of ischemic neuropathy include painful burning, sensory impairment, and reflex loss. Although ischemic peripheral neuropathy is a major complication of critical limb ischemia resulting in impaired quality of life, effective treatment for ischemic neuropathy is not available at present.

Recently, it has been reported that therapeutic angiogenesis using vascular endothelial growth factor (VEGF) gene transfer for critical limb ischemia improves ischemic neuropathy in animals or humans. Furthermore, Cuevus et al. reported that transplantation of bone marrow stromal cells improved peripheral nerve function in rats.

We reported that therapeutic angiogenesis using autologous transplantation of bone marrow mononuclear cells (BM-MNCs) for peripheral artery disease increased limb perfusion and improved clinical conditions, such as ischemic pain, claudication and ischemic ulcer. BM-MNCs contain various kinds of cell lineages, such as CD34+ cells or bone marrow stromal cells, in addition to various growth factors, such as VEGF. Thus, such cells or growth factors can work beneficially for ischemic peripheral neuropathy.

Therefore, in this chapter, we tried to clarify whether cell therapy with autologous transplantation of BM-MNCs improves ischemic neuropathy with critical ischemic limb in humans.

\section{Patients and methods}

\subsection{Study subjects}

We prospectively examined 39 patients having chronic bilateral critical limb ischemia, defined as angiographic documentation of severe large artery stenosis or occlusion associated with limb pain at rest and/or non-healing ischemic ulcers. All the patients fulfilled the inclusion criteria and did not have any exclusion criteria for therapeutic angiogenesis using BM-MNCs as described previously. Briefly, they were not candidates for non-surgical or surgical revascularization. We excluded patients with poorly controlled diabetes mellitus ( $\mathrm{HbA} 1 \mathrm{C}>6.5 \%$ and proliferative retinopathy) or with evidence of malignant disorder for the 
past 5 years. Furthermore, patients in whom neurological scales could not be evaluated due to huge ulcer or limb amputation were excluded. Finally, 14 patients undergoing autologous transplantation of BM-MNCs were enrolled in this study. Age and sex matched 23 healthy volunteers were served as controls to examine neurophysiologic scales (Healthy group). The protocol was approved by the Institutional Ethic Committee of the Kurume University. Written informed consent was obtained from all subjects.

\subsection{Collection and transplantation of BM-MNCs}

Bone marrow cells were collected from the iliac crest under general anesthesia. We sorted mononuclear cells on CS-3000 blood-cell separator (Baxter, Deerfield, USA) by a density gradient centrifugation method and concentrated them to a final volume of about $30 \mathrm{ml}$ immediately after aspiration. We injected the cells with 26-gauge needle into the gastrocunemius muscle of the more ischemic limb (treated limb), and injected saline into the opposite limb (control limb). We injected about $0.5 \mathrm{ml}$ of BM-MNCs or saline into each injection site (50 sites, $1-1.5 \mathrm{~cm}$ deep).

\subsection{Clinical features}

The severity of rest pain was described and scored by patient from 0 (none) to 10 (maximum) points using visual analogue scale (VAS). Pain free walking distance was separately measured twice as ischemic status before and 4 weeks after transplantation of BM-MNCs. Also, the detailed nature of pain was recorded to exclude symptoms that could be attributable to tissue ischemia rather than neuropathy. To distinguish neuropathic symptoms from ischemic ones, numbness, painful burning, and paresthesia in the toes of foot were defined neuropathic in origin. We excluded symptoms when they exclusively appeared during walk or by use (i.e. foot elevations). Two examiners evaluated the neurological scales. The examiners were blinded to the findings of patients' clinical profile, treatment and to each other's results. The existence of neuropathic symptom was described and scored by the patient from 0 to 1 point $(0=$ without neuropathic symptom, $1=$ with neuropathic symptom) as neurologic sensory score (NSS). We tested untreated limb to assess the natural course of the disease as control limb. Each patient was evaluated 1 week before and 4 weeks after treatment.

\subsection{Neurophysiologic scales}

Two examiners evaluated the neurological scales. The examiners were blinded to the findings of patients' clinical profile, treatment and to each other's assessment. Conduction studies were performed using techniques described elsewhere (Neuropack MEB-2200, Nihon Kohden Co. ltd, Japan). Briefly, motor nerve conduction velocities (MNCV) of the tibial nerve were measured. Tibial compound muscle action potentials (CMAP) were also recorded with surface disk electrodes from the abductor hallucis. Sensory nerve conduction velocities (SNCV) or sensory nerve action potentials (SNAP) of the sural nerve were measured. All determinations were made with the patient supine and at the surface temperature between $29-32^{\circ} \mathrm{C}$. The same examiner using the identical anatomical landmarks and distances performed repeated studies after treatment. Quantitative vibration threshold time (QVT) was measured using standard techniques by a tuning fork to determine the thresholds of vibration in the legs. We performed these neurophysiologic testing before and 4 weeks after treatment. We also measured MNCV, $\mathrm{SNCV}, \mathrm{CMAP}$ and SNAP of the healthy group at baseline. 


\subsection{Assessment of blood flow}

We measured ankle brachial pressure index (ABPI) 1 week before and 4 weeks after implantation, the ratio of simultaneously measured systolic pressure of brachial and posterior tibial arteries (ABI-form, Colin, Japan). Digital subtraction angiography (DSA) was performed with the strictly fixed amount of contrast agent, force of contrast injection, and position of the catheter tip at 1 week before and 4 weeks after transplantation. Two radiologists who were blinded to treatment evaluated collateral vessels independently. Angiograms were assessed when contrast flow in the main conducting arteries was most clearly visible. Angiographic evaluation was presented as changes in DSA score: $3+$ (rich collateral development), 2+ (moderate), 1+ (slight), 0 (no changes), and 1- (decreased).

\subsection{Statistical analysis}

Data were expressed as mean \pm SD. Differences between the two groups were analyzed by paired or unpaired Student's $t$ test when appropriate. Univariate correlations were analyzed by a Pearson's correlation. Differences with a $\mathrm{p}<0.05$ were considered statistically significant.

\section{Results}

\subsection{Patient's characteristics}

Patient's characteristics are shown in Table 1. Nine patients were Buerger's disease and 5 ASO. They all had undergone optimal medical or surgical treatment prior to this study. The average numbers of transplanted mononuclear cells of CD34 positive cells were $4.89 \pm 5.21 \times 10^{9}$ and $5.46 \pm 4.25 \times 10^{7}$, respectively (Table 1). During follow up period, no one had major adverse event, such as any cause of death and cardiovascular event.

\begin{tabular}{|c|c|c|c|c|c|}
\hline Patient & Age (y.o.) & sex & Diagnosis & $\begin{array}{l}\text { No. of } \\
\text { MNCs } \\
\left(\times 10^{9}\right)\end{array}$ & $\begin{array}{l}\text { No. of } \\
\text { CD34+ cells } \\
\left(\times 10^{7}\right)\end{array}$ \\
\hline 1 & 67 & $\mathrm{M}$ & $\mathrm{TAO}$ & 2.58 & 2.63 \\
\hline 2 & 29 & M & TAO & 2.9 & 8.48 \\
\hline 3 & 72 & $\mathrm{~F}$ & TAO & 1.07 & 0.92 \\
\hline 4 & 69 & $\mathrm{M}$ & ASO & 1.83 & 6.82 \\
\hline 5 & 43 & $\mathrm{M}$ & TAO & 4.14 & 7.18 \\
\hline 6 & 63 & $\mathrm{M}$ & ASO & 1.39 & 1.17 \\
\hline 7 & 75 & $\mathrm{M}$ & ASO & 1.70 & 5.03 \\
\hline 8 & 40 & $\mathrm{M}$ & TAO & 5.12 & 17.05 \\
\hline 9 & 61 & $\mathrm{M}$ & $\mathrm{TAO}$ & 13.5 & 3.3 \\
\hline 10 & 50 & $\mathrm{M}$ & TAO & 16.90 & 6.5 \\
\hline 11 & 62 & $\mathrm{M}$ & TAO & 11.9 & 8.3 \\
\hline 12 & 78 & $\mathrm{M}$ & ASO & 1.80 & 2.9 \\
\hline 13 & 55 & F & TAO & 2.38 & 5.1 \\
\hline 14 & 65 & $\mathrm{~F}$ & ASO & 1.20 & 1.1 \\
\hline mean \pm SD & $59.2 \pm 14.2$ & & & $4.89 \pm 5.21$ & $5.46 \pm 4.25$ \\
\hline
\end{tabular}

Abbreviations y.o.: years old, M: male, F: female, MNCs: mononuclear cells, TAO: thromboangiitis obliterans, ASO: arteriosclerosis obliterans

Table 1. Patients characteristics and number of implanted cells. 


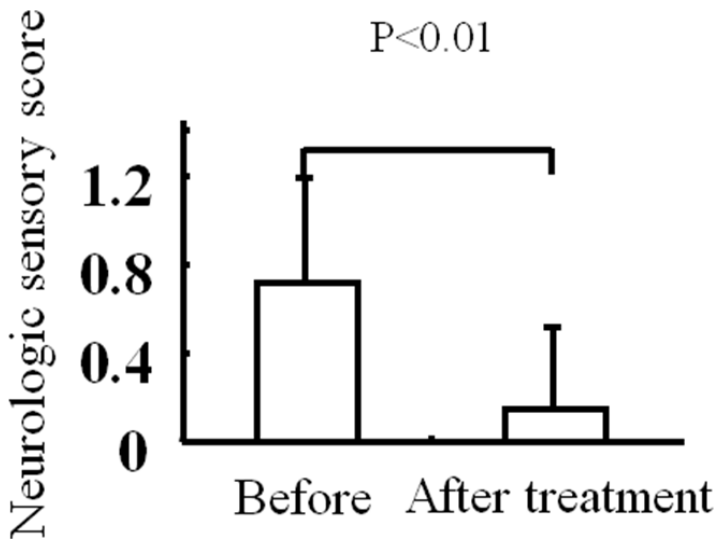

Fig. 1. Neurologic sensory score.
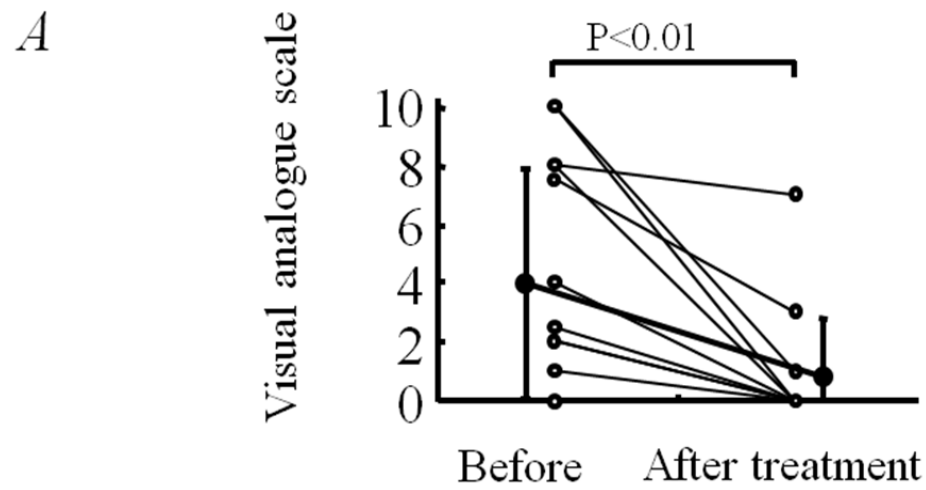

$B$

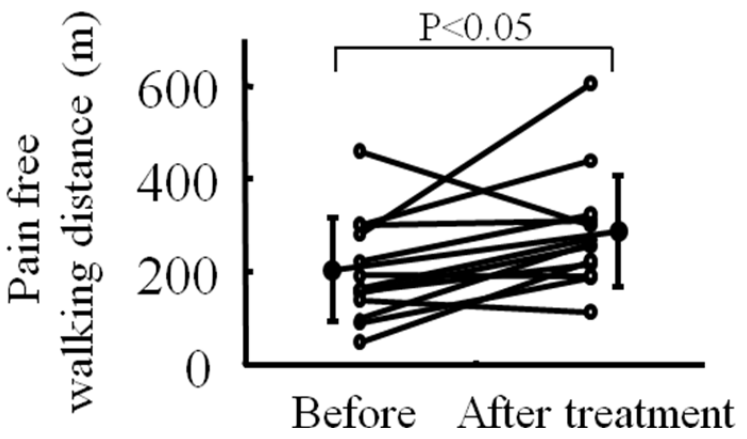

Panel A: Visual analogue scale significantly decreased one month after autologous transplantation of BM-MNCs.

Panel B: Pain free walking time significantly increased one month after autologous transplantation of BM-MNCs.

Open circles indicate individual value. Closed circle indicate average value.

Fig. 2. Improvement of ischemic symptoms. 


\subsection{Subjective symptoms}

Before treatment, 10 of 14 patients $(71.4 \%)$ had neuropathic symptoms with average NSS of $0.71 \pm 0.47$ (Figure 1). Four weeks after treatment, only 2 patients had neuropathic symptoms, and averaged NSS was decreased to $0.14 \pm 0.36$ ( $\mathrm{p}<0.01$ vs. before treatment, Figure 1). VAS significantly improved $(3.93 \pm 3.92$ to $0.79 \pm 1.79, \mathrm{p}<0.01$, Figure $2 \mathrm{~A})$ after treatment. Pain free walking distance significantly increased $(201 \pm 110$ to $317 \pm 197, \mathrm{P}<0.05$, Figure $2 \mathrm{~B})$ after treatment

\subsection{Nerve functions}

MNCV and CMAP could be measured in the treated limb of all patients, and in the control limb of 12 patients. SNCV and SNAP could be measured 11 of 14 patients in the treated $\mathrm{limb}$, and 10 of 14 patients in the control limb. Figure 3 shows the representative waveform of MNCV and CMAP before and one month after treatment. Before treatment, both MNCV and CMAP were significantly smaller in the treated limb than those in the healthy group (Table 2). Treatment significantly increased both MNCV and CMAP only in the treated limb (Table 2) but not in the control limb. MNCV was recovered to the level of healthy group but CMAP was still depressed after transplantation of BM-MNCs (Table 2). SNCV and SNAP of the patients did not differ to those of the healthy group. SNCV and SNAP were not improved by treatment (Table 2). QVT was significantly improved only in the treated limb, but not in the control limb after treatment (Table 2).
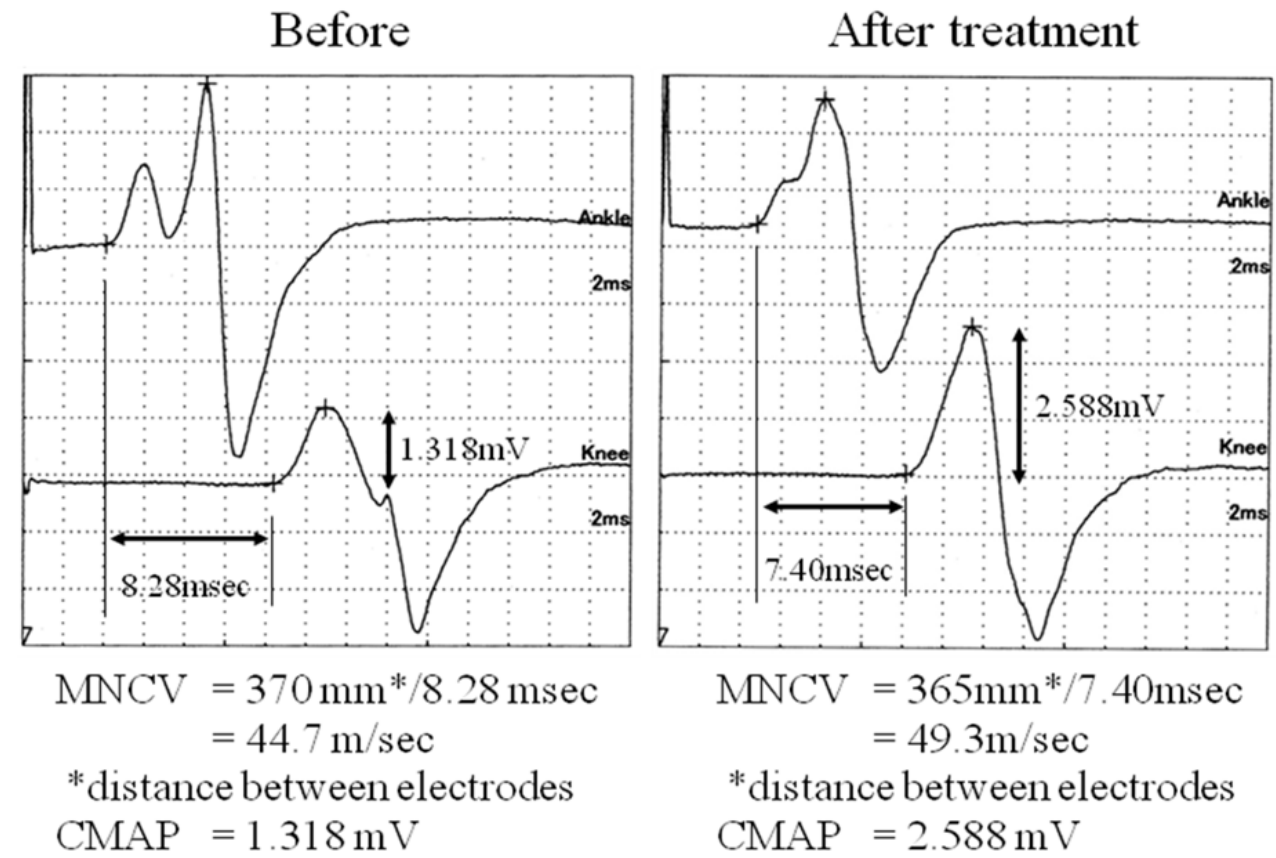

Fig. 3. Representative waveforms of MNCV and CMAP. MNCV and CMAP increased one month after autologous transplantation of BM-MNCs. 


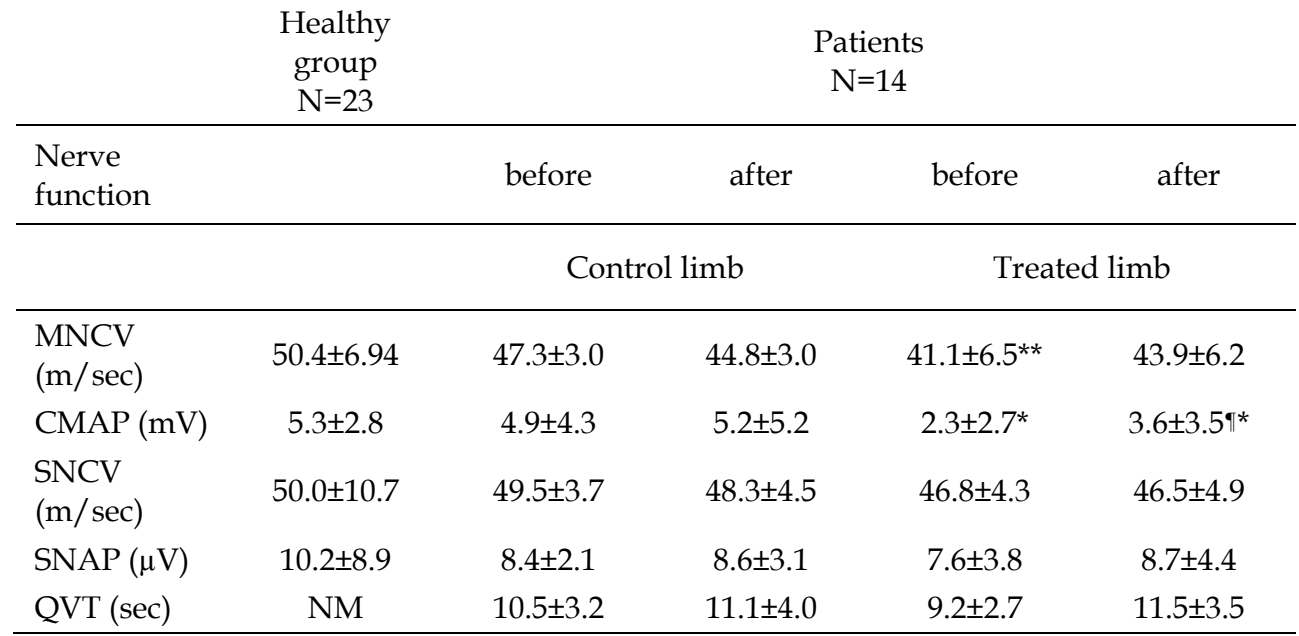

Values are expressed as mean \pm SD. Differences between the two groups were analyzed by paired or unpaired Student's t test. Univariate correlations were analyzed by a Pearson's correlation.

Abbreviations VAS: visual analogue scale, MNCV: motor nerve conduction velocity, CMAP: compound muscle action potential, SNCV: sensory nerve conduction velocity, SNAP: sensory nerve action potential, QVT: quantitative vibration threshold time. N/A: not available, NM: not measured, SD: standard deviation

${ }^{*}: \mathrm{p}<0.05$ vs. healthy group, ${ }^{* *}: \mathrm{p}<0.01 \mathrm{vs}$. healthy group, $\uparrow: \mathrm{p}<0.05 \mathrm{vs}$. before treatment, : $<<0.01$ vs. before treatment.

Table 2. Effects of nerve functions. (Based on data originally presented by Arima, K. et al.).

\subsection{Assessment of blood flow}

Before treatment, ABPI was significantly decreased in the treated and control limbs. After treatment, ABPI was significantly increased only in the treated limb $(0.59 \pm 0.24$ to $0.70 \pm 0.20$, $\mathrm{P}=0.035)$, but not in the control limb $(0.89 \pm 0.20$ to $0.89 \pm 0.20$, N.S.). DSA score in the treated limb was significantly increased after treatment $(0.0 \pm 0.0$ to $0.86 \pm 0.77, \mathrm{p}<0.05$, Figure 4$)$.

\section{Discussion}

The major findings of this study are the following two. First, autologous transplantation of BM-MNCs significantly improved subjective ischemic and neuropathic symptoms in patients with critical limb ischemia. Second, autologous transplantation of BM-MNCs improved not only peripheral blood perfusion but also peripheral nerve function.

\subsection{Neuropathy in patients with critical limb ischemia}

Several studies have reported neuropathy at the frequency of $5-31 \%$ in patients with chronic and critical limb ischemia. The mechanisms of neuropathy in patients with limb ischemia are multifocal because they have frequently have associated disease like diabetes mellitus. Weinberg et al reported that the degree of ischemia, as estimated with ABPI, correlated with clinical neuropathy. Thus it is suggested that limb ischemia is the major factor of peripheral neuropathy in patients with critical limb ischemia. 


\title{
DSA score
}

\section{$\mathrm{P}<0.05$ vs before}

\section{+2 : Markedly increased}

\section{+1 : Slightly increased}

\author{
$\pm 0:$ No change
}

-1 : Decreased

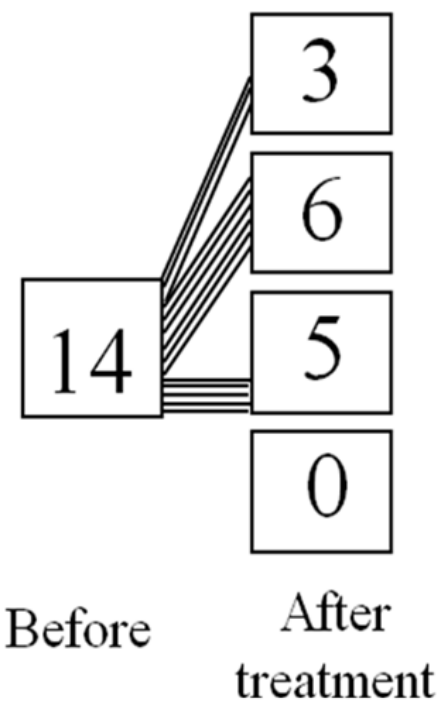

Fig. 4. Time course of DSA score after autologous transplantation of BM-MNCs in the treated limb. In the treated limb, DSA score significantly improved one month after autologous transplantation of BM-MNCs $(\mathrm{P}<0.05)$. DSA indicates digital subtraction angiography.

In this study, our patients had not only ischemic symptoms (rest pain and claudication) but also neuropathic symptoms. Because ABPI was significantly decreased and because we excluded patients with diabetes mellitus, we think the nature of neuropathic symptoms is related to limb ischemia. Furthermore, nerve function in the patients was severely impaired compared with the healthy group. Thus, the etiology of peripheral neuropathy in our patients was probably ischemic in its origin. Although our patients had bilateral limb ischemia, the nerve function at baseline was impaired only in the treated limb. The reason is not clear at present but the difference in the severity of limb ischemia may explain it.

Apart from MNCV or CMAP, SNCV and SNAP of ischemic limb before treatment were similar to those of healthy subject. The reason of such different effect of limb ischemia on motor and sensory nerves is unknown, but may be due to the size of nerve fibers. The size of motor nerve (5-15 micrometer) is larger than sensory nerve (0.5-13 micrometer). Previous pathologic studies reported that decrease in the population of large myelinated fibers was observed in ischemic peripheral neuropathy. The damage of nerve fiber may be smaller for the sensory nerve than the large motor nerve in the presence of ischemia, which may account for the preserved SNCV and SNAP. 


\subsection{Autologous transplantation of BM-MNCs improved neuropathy}

Recently, we reported that autologous transplantation of BM-MNCs increased limb perfusion and improved symptoms and ulcers in human ischemic limb. In this study, we confirmed our previous findings that autologous transplantation of BM-MNCs significantly improved ABPI and DSA score in treated limbs. This treatment significantly improved not only ischemic pain (VAS, pain free walking time) but also neuropathic symptoms. Furthermore, transplantation of BM-MNCs significantly improved objective peripheral nerve functions (MNCV, CMAP and QVT) in the treated limb, but saline injection did not affect the nerve functions. These results indicated that the effects of the treatment were not related to natural course or non-specific effects. Thus, it is concluded that autologous transplantation of BM-MNCs improved not only peripheral blood perfusion but also ischemic peripheral neuropathy.

\subsection{Mechanisms of improvement of peripheral neuropathy}

The several mechanisms may contribute to the improvement of peripheral nerve function. First, the improvement may be caused by better blood perfusion after autologous transplantation of BM-MNCs. On this issue several conflicting results were reported.

There were several therapeutic strategies for improving blood perfusion, such as surgical revascularization or therapeutic angiogenesis induced by VEGF gene transfer. Hunter et al. examined electrophysiological changes of nerves after surgical revascularization. They reported no improvement of multiple electrophysiological outcome measures after surgical revascularization, suggesting that ischemic neuropathy may be an irreversible condition. On the other hand, Simovic et al. reported that VEGF gene transfer improved the neuropathic symptoms, CMAP and QVT, but not nerve conduction velocity. They speculated that the differences of efficiency between surgical revascularization and VEGF gene transfer were related to the size of restored vessels after treatments. In fact, surgical revascularization mainly restores blood flow of large vessels, and neovascularization from angiogenic cytokines, such as VEGF, principally involves small vessels including the vasa-nervorum ( $<180$ micrometer), the nutrient arteries of peripheral nerves. Furthermore, it is reported that VEGF gene transfer improves peripheral nerve perfusion and function through regeneration of vasa-nervorum in rats with streptozotocin-induced diabetes. In this study, electrophysiological study showed improvement of nerve functions in addition to neuropathic symptoms. It is reported that variety of cytokines, such as VEGF, are contained in transplanted bone-marrow fluid or secreted by transplanted BM-MNCs. Thus, such various angiogenic cytokines might have improved nerve perfusion and function in this study.

Second, nerve regeneration might have occurred after transplantation of BM-MNCs. It is reported that VEGF also has regenerative and protective function for peripheral nerve. Furthermore, Cuevas et al. reported that implantation of bone-marrow stromal cells improved peripheral nerve function via nerve regeneration in animals. They reported that implanted cells participated in nerve regeneration through their differentiation in Schwannlike cells and also in the production of trophic factors. Because transplanted BM-MNCs used in this study presumably contain various kinds of cells such as bone-marrow stromal cells as previously reported, it may be speculated that transplantation of BM-MNCs might have regenerated the damaged peripheral motor nerve. Of course, we have no evidence.

Limitations of this study need to be addressed. First, this study was an observational openlabel study with no placebo control group. Next, the number of patients enrolled in this 
study was small. Further large sized controlled clinical study is needed to confirm our findings. Finally, we treated patients with critical limb ischemia who had undergone optimal medical and surgical treatment. Thus, it is not known whether autologous transplantation of BM-MNCs is effective for the earlier stage of patients.

\section{Conclusions}

In conclusion, these results suggested that cell therapy with autologous transplantation of BM-MNCs improves ischemic neuropathy with critical ischemic limb in humans.

\section{Acknowledgement}

This study was supported in part by Kimura Memorial Heart Foundation Research Grant: by grants for Cardiovascular Disease (16C-6) from the Ministry of Health, Labor, Welfare: by a Grant for Science Frontier Promotion Program and Grants-In-Aid from the Ministry of Education, Culture, Sports, Science, and Technology of Japan. We thank Kimiko Kimura for technical assistance.

\section{References}

Arima, K. \& Katsuda, Y. \& Takeshita, Y. \& Saito, Y. \& Toyama, Y. \& Katsuki, Y. \& Ootsuka, M. \& Koiwaya, H. \& Sasaki, K. \& Kai, H. \& Imaizumi, T. (2010). Autologous transplantation of bone marrow mononuclear cells improved ischemic peripheral neuropathy in humans, J. Am. Coll. Cardiol, Vol. 56, No. 3, (July 2010), pp. 238-239, ISSN 0735-1097

Cahill, BE. \& Kerstein MD. (1987). Ischemic neuropathy. Sug Gynecol Obstet Vol.165, No. 5, (November 1987 ), pp. 469-74, ISSN 0039-6087

Cuevas, P. \& Carceller, F. \& Dujovny, M. \& Garcia-Gomez, I. \& Cuevas, B. \& GonzalezCorrochano, R. \& Diaz-Gonzalez, D. \& Reimers, D. (2002) Peripheral nerve regeneration by bone marrow stromal cells. Neurol Res. Vol. 24, No. 7, (October, 2002), pp. 634-8, ISSN 0161-6412

Cuevas, P. \& Carceller, F. \& Garcia-Gomez, I. \& Yan, M. \& Dujovny, M. (2004). Bone marrow stromal cell implantation for peripheral nerve repair. Neurol Res. Vol. 26, No. 2, (April, 2004), pp. 230-2, ISSN 0161-6412

Farinon, AM. \& Marbini, A. \& Gemignani, F. \& Govoni, E. \& Bragaglia, MM. \& Sianesi, M. \& Tedeschi, F. (1984) Skeletal muscle and peripheral nerve changes caused by chronic arterial insufficiency - Significance and clinical correlations - Histological, histochemical and ultrastructural study. Clin Neuropathol. Vol. 3, No. 6, (November 1984 ), pp. 240-52, ISSN 0722-5091

Hunter, GC. \& Song, GW. \& Nayak, NN. \& Zapotoxski, D. \& Guernsey, JM. (1988) Peripheral nerve conduction abnormalities in lower extremity ischemia: the effects of revascularization. J Surg Res. Vol. 45, No. 1, (July 1988), pp. 96-103, ISSN 00224804

Isner, JM. \& Pieczek, A. \& Schainfeld, R. \& Blair, R. \& Haley, L. \& Asahara, T. \& Rosenfield, K. \& Razvi, S. \& Walsh, K. \& Symes, JF. (1996). Clinical evidence of angiogenesis after arterial gene transfer of ph VEGF165 in patient with ischaemic limb. Lancet. Vol. 348, No. 9034, (Aug 10), pp. 370-374, ISSN 0140-6736 
Kamihata, H. \& Matsubara, H. \& Nishiue, T. \& Fujiyama, S. \& Tsutsumi, Y. \& Ozono, R. \& Masaki, H. \& Mori, Y. \& Iba, O. \& Tateishi, E. \& Kosaki, A. \& Shintani, S. \& Murohara, T. \& Imaizumi, T. \& Iwasaka, T. (2001). Implantation of bone marrow mononuclear cells into ischemic myocardium enhances collateral perfusion and regional function via side supply of anigioblasts, angiogenic ligands, and cytokines. Circulation. Vol. 104, No. 9, (August 2001), pp. 1046-52, ISSN 1524-4539

Mufson, I. (1952) Diagnosis and treatment of neural complications of peripheral arterial obliterative disease. Angiology, Vol. 3, No. 5, (October 1952), pp 392-3, ISSN 00033197

Saito, Y. \& Sasaki, K. \& Katsuda, Y. \& Murohara, T. \& Takeshita, Y. \& Okazaki, T. \& Arima, K. \& Katsuki, Y. \& Shintani, S. \& Shimada, T. \& Akashi, H. \& Ikeda, H. \& Imaizumi, T. (2007) Effect of autologous bone-marrow cell transplantation on ischemic ulcer in patients with Buerger's disease. Circ J. Vol. 71, No. 8, (July 2007), pp. 1187-92, ISSN 1346-9843

Schratzberger, P. \& Schratzberg, G. \& Silver, M. \& Curry, C. \& Kearney, M. \& Magner, M. \& Alroy, J. \& Adelman, LS. \& Veinberg, DH. \& Ropper, AH. \& Isner, JM. (2000). Favorable effect of VEGF gene transfer on ischemic peripheral neuropathy. Nat Med. Vol. 6, No. 6, (March 2000), pp. 405-13, ISSN 1078-8956

Schratzberger, P. \& Walter, DH. \& Rittig, K. \& Bahlmann, FH. \& Pola, R. \& Curry, C. \& Silver, M. \& Krainin, JG. \& Weinberg, DH. \& Ropper, AH. \& Isner, JM. (2001) Reversal of experimental diabetic neuropathy by VEGF gene transfer. J Clin Invest. Vol. 107, No. 9, ( May 2001), pp. 1083-92, ISSN 0021-9738

Simovic, D. \& Isner, JM. \& Rooper, AH. \& Pieczedk, A. \& Weinverg, DH. (2001). Improvement in chronic ischemic neuropathy after intramuscular phVEGF165 gene transfer in patients with critical limb ischemia. Arch Neurol, Vol. 58, No. 5, ( May 2001), pp. 761-8, ISSN 0003-9942

Strokebaum, E. \& Lambrechts, D. \& Carmeliet P. (2004). VEGF: once regarded as a specific angionenic factor, now implicated in neuroprotection. Bioessays. Vol. 26, No. 9, (September 2004), pp. 943-954, ISSN 0265-9247

Tateishi-Yuyama, E. \& Matsubara, H. \& Murohara, T. \& Ikeda, U. \& Shintani, S. \& Masaki, H. \& Amano, K. \& Kishimoto, Y. \& Yoshimoto, K. \& Akashi, H. \& Shimada, K. \& Iwasaka, T. \& Imaizumi, T. (2002). Therapeutic angiogenesis for patients with limb ischaemia by autologous transplantation of bone-marrow cells: a pilot study and a randomized controlled trial. Lancet. Vol. 360, No. 9331, (August 2002), pp. 427-35, ISSN 0140-6736

Weinberg, DH. \& Simovic, D. \& Isner, J. \& Ropper, AH. (2001). Chronic ischemic monomelic neuropathy from critical limb ischemia. Neurology, Vol. 57, No 6, (September 2001), pp. 1008-12, ISSN 00283878 


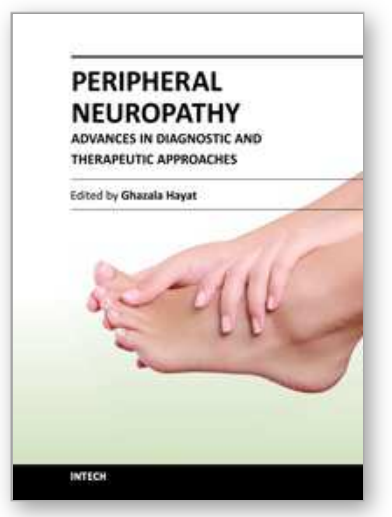

\section{Peripheral Neuropathy - Advances in Diagnostic and Therapeutic Approaches}

Edited by Dr. Ghazala Hayat

ISBN 978-953-51-0066-9

Hard cover, 206 pages

Publisher InTech

Published online 29, February, 2012

Published in print edition February, 2012

Over the last two decades we have seen extensive progress within the practice of neurology. We have refined our understanding of the etiology and pathogenesis for both peripheral and central nervous system diseases, and developed new therapeutic approaches towards these diseases. Peripheral neuropathy is a common disorder seen by many specialists and can pose a diagnostic dilemma. Many etiologies, including drugs that are used to treat other diseases, can cause peripheral neuropathy. However, the most common cause is Diabetes Mellitus, a disease all physicians encounter. Disability due to peripheral neuropathy can be severe, as the patients suffer from symptoms daily. This book addresses the advances in the diagnosis and therapies of peripheral neuropathy over the last decade. The basics of different peripheral neuropathies is briefly discussed, however, the book focuses on topics that address new approaches to peripheral neuropathies.

\section{How to reference}

In order to correctly reference this scholarly work, feel free to copy and paste the following:

Yousuke Katsuda, Ken Arima, Hisashi Kai and Tsutomu Imaizumi (2012). Cell Therapy for Ischemic Peripheral Neuropathy, Peripheral Neuropathy - Advances in Diagnostic and Therapeutic Approaches, Dr. Ghazala Hayat (Ed.), ISBN: 978-953-51-0066-9, InTech, Available from: http://www.intechopen.com/books/peripheralneuropathy-advances-in-diagnostic-and-therapeutic-approaches/cell-therapy-for-ischemic-peripheralneuropathy

\section{INTECH}

open science | open minds

\author{
InTech Europe \\ University Campus STeP Ri \\ Slavka Krautzeka 83/A \\ 51000 Rijeka, Croatia \\ Phone: +385 (51) 770447 \\ Fax: +385 (51) 686166 \\ www.intechopen.com
}

\author{
InTech China \\ Unit 405, Office Block, Hotel Equatorial Shanghai \\ No.65, Yan An Road (West), Shanghai, 200040, China \\ 中国上海市延安西路65号上海国际贵都大饭店办公楼 405 单元 \\ Phone: +86-21-62489820 \\ Fax: $+86-21-62489821$
}


(C) 2012 The Author(s). Licensee IntechOpen. This is an open access article distributed under the terms of the Creative Commons Attribution 3.0 License, which permits unrestricted use, distribution, and reproduction in any medium, provided the original work is properly cited. 